\title{
Biomass from willow plantation as a source of renewable energy and reduction of smog emissions
}

\section{Michał Jasiulewicz (10)}

Koszalin University of Technology ul. Śniadeckich 2, 75-453 Koszalin

michal.jasiulewicz@tu.koszalin.pl

\begin{abstract}
In the paper, the Author has presented the activity of the Koszalin University of Technology and the experience concerning its willow plantation. Creating a network of power and heating stations should not only affect the climate and energy safety but first of all contribute to a sustainable entrepreneurial development of rural areas. The Koszalin University of Technology has been conducting experiments and implementing new technologies on its 92.0 ha willow plantation. During the last two years, there has been a research project carried out aiming at the following among others:

- use of sewage residues and municipal organic waste as manure in plantation;

- selection of plants with the most efficient growth and energy performance, taking into account technical, environmental and economical aspects.

Next year, the co-combustion at a local district heating plant for thermal energy will be launched and, in five years' time, cogeneration solutions: a power plant and a district heating system based on biomass energy gasification will be introduced.

Scientific innovation and significance:

- potential of using fallow soils for willow plants;

- research into the selection of different willow clones: the highest biomass gain;

- use of sewage and municipal organic waste residues as manure in the plantation;

- cooperation with the Heating Plant and the Municipal Plant: to establish a plant for heat production.
\end{abstract}

Keywords: willow, biomass production, energy market.

\section{Introduction}

Biomass is one of the most promising energy sources in the EU, particularly in Poland. Arguments of the EU access contract indicate a need of increasing renewable energy production, including raw materials based on biomass use. There are many solutions for issues related to the potential of biomass. Biomass energy has been recognized as one of the most promising and most important renewable energy sources in the near future for Polish conditions (Alfonso et al. 2008).

The total technical potential of biomass resources has been estimated to be 895 PJ (EC EBMER, 2005) (Jasiulewicz 2010). The largest resources are related to the agricultural and forestry residues as well as forestry fuel wood. Energy crops and willow plantations are expected to play a more important role in the mid- and long-term perspective. 
Biomass could be produced in sufficient quantities on the whole area of the country while having hardly any competition. The electric energy sector in Poland is based in $97 \%$ on coal, as nowhere else.

About $65 \%$ of district heating in Polish towns is provided by centralized installations, which supply annually 270 to 300 PJ of heat energy. At present, the installed power of biomass, i.e. fired heating systems, can be estimated to be ca. $1 \mathrm{GW}$. According to current forecasts, it is expected to increase up to $10 \mathrm{GW}$ by 2030.

Thus, initiatives aiming at renewable energy sources may be almost unlimited. The potential of the production and usage of biomass for power and thermal energy seems to be unlimited, as well.

\section{Sustainable development in rural areas}

Biomass energy has been recognized as the most promising and essential renewable energy source in near future for Polish conditions. Local climate conditions, low quality of soils and free manpower in rural areas create unique circumstances to cultivate energy plants to be used in the energy production process. The utilisation for energy production of cultivated plants in communal heating plant addresses directly the priority thematic areas in the EU concerning sustainable development, global change and ecosystems. First of all, it fits the aim of an alteration of the European energy sector structure; in this specific case, by means of biomass production from cultivated energy plants, that would lead to an increased percentage of energy production from renewable energy sources. The solutions proposed, once implemented, will contribute to lowering the harmful components of fuel fumes, resulting in a positive influence on environmental protection. The sustainable energy system shall be included into the energy supply chain. It is very important not only to lower the costs of currently used conventional fuel and environmental impact but also to disseminate methods of restoring low-use lands into agricultural cultivation. There is a social context attached to this issue, related to increased economic interest in rural areas, associated with the expansion of labour market. From this perspective, it may be expected that the project outcomes possess a competitive dimension compared to current conventional energy sources. The technological solutions presented herein are of a multidisciplinary nature as they take into account the whole chain from preparing the land and planting up to their utilisation for energy production in a communal heating plant.

Arguments of the EU access contract indicate a need of increasing renewable energy production, including production from raw materials based on biomass usage. Practical and theoretical solutions of the issues related to biomass potential in its various forms require close co-operation of science and economy in the most efficient way. In most of the EU member countries, as in Poland, there is a significant surplus of agricultural output, of which production, storing and export subvention costs constitute large amounts in the EU's and domestic budgets. The percentage of fallow grounds in relation to the arable lands in Poland is high: ca. 10\%. Also marginal grounds (LFA) used for agriculture production, i.e. consumption of food products, represent a significant part (Bioenergie... 2007). Thus, utilizing such lands, in Poland or in other EU countries, for energy plants cultivation (willow etc.) of relatively low soil requirements, for which LFA and fallow grounds are ade- 
quate for planting, creates a potential to exploit unused lands. An increasing issue on the EU and global scale is a fast increase of communal refuse and sewage residues, as well as the problem of their neutralization. There are many unsolved or not fully verified research problems related to biomass: production, manure with sewage residues communal refuse, co-combustion with coal, turning it into gas (Baum i Wielicki 2009).

\section{Potential of utilizing fallow grounds for energy plants cultivation}

Marginal grounds (LFA) used for agriculture production, i.e. consumption food products, represent a significant part (in Poland about 40\%). Therefore, utilizing such lands in Poland or in other EU countries for energy plants cultivation (willow, rosa, miscanthus, etc.) of relatively low soil requirements, for which LFA and fallow grounds are adequate for growth, creates a potential to take advantage of lands that are left unused nowadays (Brewer et al. 2007).

Solid biofuels should be used in local power stations and hot water used for heating flats in small towns. Thus, the best solution would be to establish a network of local power and heating stations. It is possible to utilize fallow soil to cultivate willow or poplar, being an important factor for the sustainable development of rural areas and entrepreneurial regions. Creating a network of power and heating stations should positively affect human-related environmental changes and provide energy safety. Moreover, it is expected to foster sustainable entrepreneurial development of rural areas.

Utilization of raw biomass near plantations is necessary because of transport costs and environmental protection (Jasiulewicz 2008). It is possible to burn biomass and use the energy in communal heating, particularly in small towns, where the heating infrastructure used in relation to apartment buildings is already functioning. It is possible to combine biomass with coal, in order to improve air quality (environmental aspects) by utilizing the existing heating infrastructure.

The most efficient utilization of biomass is gasification and converting the energy into electricity, and water-cooling should be used to heat apartments in towns. It is very important to utilize the biomass near plantations or other sources of biomass.

\section{Implementation of willow plantation at the Koszalin University of Technology and its result}

Research teams have been jointly running experiments and implementing new technologies for the purpose of the scientific project conducted. The link between science and practice constitutes a very important element of the project, i.e. an implementation of the latest research achievements in economy.

In the case of necessity for special requirements, it is expected to employ specialists, institutes and implementation companies, both from Poland and other countries. This would lead to the use of the latest scientific and implementation solutions. In the project, there are many results from various disciplines expected to be achieved, including the following among others (Jasiulewicz 2010): 
- Utilizing of sewage residues and communal organic refuse as manure on the plantation.

- Selection of plants of the most efficient growth and energy performance, taking into account technical, environmental and economic aspects.

- Finding solutions to many technical, technological and economic issues related to the co-combustion of coal with biomass.

- Description of utilizing the thermal energy surplus for power production, as an effect of converting biomass into gas.

- Converting a communal heating plant into a heat and power generating plant based on biomass as a raw material.

- A high biomass demand would ensure using marginal soils (LFA) and guarantee a continuity of supplies and power production.

This effect should contribute to establishing numerous work-places in rural areas (production, harvest, transport) and their activation, utilization of fallow grounds. Small and medium local heat and power generating plants will be developed, ensuring energy self-sufficiency. The project includes complex research related to using biomass as an energy raw material, i.e. from the cultivation of energy plants, manure with residues from purification plants and from communal dumping grounds, through carrying, harvest, transportation, preparation for processing, to usage as an energy source (co-combustion, convertion into gas) (Jasiulewicz 2005).

Implementation of the scientific research and experiments for practical usage of biomass for the production of thermal energy and power should stimulate common utilization of fallow grounds and other LFA grounds for setting energy plant plantations.

In 2005, the Koszalin University of Technology established a new plantation of willow in fallow areas of 31.5 ha and later (2007) included another 61 ha, a total of 92 ha. After summer time, in November 2005, all of the willow was cut. 2006 was the first year of the growth for biomass; the willow growth rate is presented in the table below.

Table 1. Average rate of willow growth in 2006 (cm)

\begin{tabular}{|l|r|r|r|r|r|r|}
\hline \multicolumn{1}{|c|}{ Clone } & 1047D & $\mathbf{1 0 1 3}$ & $\mathbf{1 0 4 7}$ & $\mathbf{1 0 5 2}$ & $\mathbf{1 0 5 4}$ & $\mathbf{1 0 2 3}$ \\
\hline 31.05. Height & 69.9 & 49.1 & 77.0 & 64.9 & 70.2 & 60.5 \\
Daily growth & 2.2 & 1.6 & 2.5 & 2.1 & 2.7 & 1.9 \\
09.06. Height & 89.6 & 64.7 & 95.7 & 85.2 & 94.4 & 87.1 \\
Daily growth & 2.2 & 1.7 & 2.1 & 2.3 & 2.7 & 2.9 \\
19.06. Height & 116.4 & 92.6 & 142.6 & 124.8 & 141.2 & 119.8 \\
Daily growth & 2.6 & 2.9 & 4.7 & 3.9 & 4.7 & 3.3 \\
30.06. Height & 152.8 & 136.0 & 167.8 & 146.4 & 175.0 & 142.6 \\
Daily growth & 3.3 & 3.9 & 2.3 & 1.9 & 3.1 & 2.1 \\
17.07. Height & 177.8 & 157.4 & 206.8 & 154.4 & 198.4 & 152.6 \\
Daily growth & 1.5 & 1.2 & 2.3 & 0.5 & 1.4 & 0.6 \\
01.08. Height & 189.0 & 166.0 & 215.2 & 158.0 & 210.0 & 161.0 \\
Daily growth & 0.8 & 0.6 & 0.6 & 0.2 & 0.8 & 0.4 \\
\hline
\end{tabular}

Source: author's own calculations. 


\section{Next steps}

The biomass produced should be used in local heat and power generating plants that may supply the local environment with thermal energy, and the surplus should be converted into electric power and supplied to the national power grid. Following this pattern, the local systems would be self-sufficient in terms of energy.

Many new non-agricultural workplaces will be created in rural areas. This activity will improve their social status, being a source of additional income. The state of environment in th rural areas (water, soil, air quality) should significantly improve, as well.

Biomass production and its conversion into energy - disseminated on a large scale should be an important factor of the activation of rural areas, especially in areas of low agricultural value and high unemployment.

The activity coordinated by the project through its contribution to the economy should enable all those interested to become acquainted with the complete production cycle, i.e. from planting seedlings up to the final product: thermal energy and power generation (co-combustion with coal, converting it into biogas and conversion into thermal and electric energy). It may become an important factor especially for underdeveloped regions. An implementation of energy production based on biomass would offer a great chance to the whole Zachodniopomorskie (West Pomeranian) Voivodship and to other areas of Poland as well as to EU member states in activating development.

Farmers constitute an important target group of the project results implementation and demonstration. Currently, they are highly interested in biomass production; however, lack of utilization potential makes organizing the production on an industrial scale hardly feasible. Demonstrating activities focused directly on energy plantation are of a great significance. Farmers will be introduced to various phases of vegetation and harvesting as well as during biomass conversion.

The research results, including new verified technologies of combustion, co-combustion, and conversion of biomass into gas, will be of a great significance to current thermal energy producers as regards the issue of gaining energy from biomass.

The project consortium ensures disseminating results in the energy sector in the Zachodniopomorskie (West Pomeranian) Voivodship by a number of small and medium heating plants producing thermal energy for local market purposes.

Scientific innovation and significance:

- potential of utilizing fallow soils for willow plants;

- research of the selection of various willow clones: the most efficient biomass production;

- utilization of sewage residues and communal organic refuse as manure in the plantation;

- cooperation with heating and communal companies - to create the market for biomass.

\section{Low emissions, smog}

A phenomenon that is frequently related to economic use is low emissions, which is especially observed in autumn and in winter. This is a type of wood that originates from vario- 
us fuel wastes in the system of individual heating of houses and household installations. Rural areas in Poland are inhabited by $38.8 \%$ of the population, these have enormous resources and can become energy self-sufficient (in terms of heat and electricity production). It is necessary to strive to use this potential and pursue the considerations of research to achieve self-sufficiency.

Such actions are aiming at reducing the costs of energy and heat supply used in agriculture. Farms using modern technology and renewable resources, energy sources (biomass, wind energy, solar energy), are profitable in prosumer projects, as well as in the development of cooperatives in villages.

When planning energy projects in rural areas, the possibility of support from public funds and the EU should be taken into account; however, the economic justification of the project is necessary. It is important to apply the most recent technologies taking into account sustainable development.

For many years now, in the European Union, as well as in Poland, many actions have been taken to promote an economic growth and sustainable development of rural areas, where the main principle was to move towards an economy that efficiently uses resources that are friendly to humans and harmless to the environment.

It is widely accepted that bio-economy includes the production of renewable bio-based resources on lands and in seas, as well as the use of these resources and waste streams to produce added-value products such as food, feed, bio-based products, biomaterials and bioenergy. The use of bio-economy in the development of rural areas and counteracting excessive emissions should be considered as a great opportunity, both in the socio-economic aspect, as well as for ecological and sustainable development.

The problem of low smog emissions is related to large areas in Poland. Low emissions include pollutants emitted from sources up to $40 \mathrm{~m}$ (from the ground surface); these are mainly pollutants related to human activity, emitted by outdated heating devices in single-family houses, apartments in multi-family buildings and farm buildings. This phenomenon is a serious ecological, social and health problem to local communities.

In Poland, compared to most European Union (EU) countries, the main source of air pollution, especially in rural areas, is not traffic smog, but heating in residential buildings: a total estimated at approx. 5 million tonnes. Low hard coal burned in boilers and stoves of poor quality produces significant amounts of waste (including chemical waste), creating fumes and dust at low altitudes, i.e. up to $40 \mathrm{~m}$ from the surface, which have a very detrimental effect on the health of nearby residents. Of course, the problem of low emissions also applies to cities; hence, in terms of air pollution, Poland is at the forefront of the EU; from among the most polluted European cities, over 30 are located in Poland. Solving this problem in larger cities requires slightly different solutions than in the case of rural areas (including cities up to 10,000 inhabitants). Rural areas, which cover an area of approx. 93\% of Poland's territory, present various potentials of using renewable energy sources (RES). However, in this article, the Author draws attention mainly to the possibilities of using local biomass for energy purposes. Employing biomass in the production of electricity and heat should be seen through many dimensions. An essential step forward in the effective use of biomass in the energy sector should be the development of local distributed energy centres located in small towns and larger rural settlements. Biomass obtained is expected to come from local sources, i.e. forest waste, roadside tree felling, waste and by-products from agricultural and processing industrial production, wa- 
ste from slaughterhouses, municipal "bio" waste, waste and by-products from agriculture, gastronomy, sewage sludge, etc.

In Poland's rural areas, especially those with the predominance of agriculture, there are many wastes and by-products that can be used with the latest co-generation technologies to a high degree of energy and economic efficiency (both plant and animal waste in liquid and solid forms).

As a general rule, large-scale models have been developed for the use of biomass for energy purposes, proven in practice, in two different formats.

1. Effective biotechnology, i.e. the use of fermentation gasification of energy plants with an addition of substrates in the form of waste biomass from agricultural production (slurry, manure, plant residues), waste from slaughterhouses, sewage sludge, waste from agri-food industry. As a result, it is possible to obtain biogas that can be directly used in gas engines that feeds into power generators, most often with a capacity of 200-800 $\mathrm{KW}$. At the same time, hot water from the cooling system in the cogeneration system is used to supply heating systems: municipal, industrial and other (e.g., Nacław, commune of Polanów - Poldanor company). Animal faeces constitute an important raw material for the production of biogas: 1 large (SD) livestock produces approx. $50 \mathrm{~kg}$ of slurry per day. The yield of slurry as a substrate component in a biogas plant is approximately $25 \mathrm{~m}^{3}$ of biogas from $1 \mathrm{~m}^{3}$ of slurry. It is estimated that farms in Poland produce about 35-38 million $\mathrm{m}^{3}$ of slurry annually, of which at least $30 \%$ can be used as a raw material in a biogas plant. Also, slaughterhouse remnants in Poland are on the level of approx. 660 thousand tonnes/year, and they constitute an important component of substrate in biogas production.

It should also be borne in mind that there is a significant acreage of meadows that are not used for agricultural production (approx. 1 million ha), of which, mown meadows comprise approx. 1139300 thousand m³year and 1708950 thousand m³/year of biogas. The potential of fermentation biogas plants in Poland (taking into account the location of at least 1 biogas plant in the commune) is estimated at 3,000 MW. Taking into account the use of the peak power of 6,000 h/year, it offers the possibility of annual production of approx. 44 TWh of energy, 18 TWh of electricity and 26 TWh of thermal energy. One of the crops considered to be the most efficient in the process of biogas fermentation is maize. Assuming commissioning in Poland by 2030. approx. 3,000 biogas plants and allocating approx. 200 ha of arable land to each of them - it should make together - approx. 600 thousand ha of land. An important issue is to take into account the need for maize sowing - relatively good soils, which should not be a serious problem in agriculture. An important issue is the location of fermentation and agricultural biogas plants, i.e. it would be most advantageous to install biogas plants mainly near farms: cattle, pigs, i.e. in a place with a large amount of slurry collected (the possibility of an economic use of livestock waste), the disposal of which (agricultural use) is of a great concern. In the recent years, small biogas plants ( $<1 \mathrm{MW}$ ) have been developing, and neighbouring ones: a shared location, as well as cooperatives for a larger number of small and medium-sized farms. In new installations, attention is paid to the use of a co-generation system, i.e. ensuring an on-site use of heat generated from the cooling system of the gas engine and power generator. Collection of electricity should be largely used on site in the biogas plant and in the surrounding area and, as a result of the connection with the national energy system, with the possibility of selling excess electricity to the national grid. New 
installations also use heat recovered from chimney systems (recuperation). The post-fermentation sludge is also very important: in the liquid form, the fertilizer is suitable for use in agriculture. It is also possible to obtain "eco" solid fertilizers in the further post-fermentation drying process.

2. As a result of the palletization process, pellets can also be obtained from post-fermentation sludge, in a solid state, suitable for combustion, both in boilers in small single-family houses, as well as in heating system boilers, especially in small towns and housing estates. It is an important issue that enables the replacement of hard coal, commonly used as an energy raw material, with biomass pellets (on a larger scale: wood chips).

The (agricultural) biogas fermentation system provides the opportunity to use thermal energy on site - which has a large impact on the level of energy and economic efficiency. An example of this type of cogeneration biogas installation can be a biogas plant operating on raw material in the vicinity of a distillery, which produces about 11 million litres of spirit annually, mainly using maize. The stillage from the distillery as a substrate is transported by conveyor belts to the biogas plant located in the vicinity. The biogas produced is purified and used in a gas engine ( $2 \mathrm{MWe}$ ), with a power generator: to produce electricity for one's own needs and as a result of the merger, the surplus is transferred to the national grid. The use of water in a closed circuit is noteworthy, the purified sediments constitute an optimal environment for the development of algae, which are a valuable contribution to the substrate. The heat from the exhaust gases (recuperation) is reused in the boiler recovered in the production technology in the distillery - transmission over a short distance. The semi-liquid digestate obtained at the final stage is dried and pelletized to produce an "eco" fertilizer, which is sold. What is noteworthy, carbon dioxide $\left(\mathrm{CO}_{2}\right)$ is also separated and then stored, which is sold on the market.

\section{Conclusions}

Utilizing land in Poland or in other EU countries for energy plants cultivation (willow, rose, miscanthus etc.) of relatively low soil requirements, for which LFA and fallow grounds are adequate for growth, provides a great opportunity to exploit lands that have not been used up to now.

Biomass should be consumed in local power plants in small towns. Heating flats is anticipated to be carried out with hot water. Creating a network of power and heating stations should not only mitigate negative human-related effects on the climate. It will also ensure safety of electricity and heating. Moreover, it is expected to foster development of rural areas and small towns, many SME and job places. This initiative contributes to sustainable entrepreneurial regional development.

The solution proposed provides a great opportunity to utilize fallow soils by establishing a plantation of energy plants. Production of biomass by means of sewage residues and communal organic refuse as a manure on the plantation is expected to give rise to the biomass market.

EU indicates a need to increase renewable energy production including biomass use. Practical and theoretical solutions related to the biomass use require close cooperation between science and economy. 
Fallow grounds shares of arable lands in Poland are high, about $10 \%$. Also marginal grounds (LFA) used for agriculture production, i.e. consumable food products, represent a significant part: approximately $40 \%$. Utilizing such lands in EU countries for energy plants cultivation provides a great opportunity. LFA and fallow grounds are adequate for growth of willow, poplar and miscanthus because of their low soil requirements.

\section{Bibliography}

Alfonso, D., Peroina, C., Perez-Navarro, A., Penalvo, E., Cardenas, R., Vargas, C. (2008). Biomass Resources Evalution and Optimization of its Management and Final Energy Generation: Methodology and Application. 16th European Biomass Conference \& Exhibition (p. 327-331). Valencia, Spain.

Baum, R., Wielicki, W. (2007). Prognoza przeobrażeń rolnictwa do roku 2030 w Kontekście zrównoważonego rozwoju. Wieś $i$ Rolnictwo, 1.

Bioenergie, Planzen, Rohstoffe, Produkte. (2007). Fachagentur Nachwachsende Rostoffe, E.V. (FNR). Bundesministerium fur Ernahrung, Landwirtscheft und Verbraucherschutz.

Brewer, A.C., Morgan, G., Poole, E.J., Baldwin, M., Tubby, I. (2007). Predictive Models of Biomass for Poplar and Willow, Short Rotation Coppice in the United Kingdom, Bioenergy 2007, 3rd International Bioenergy Conference and Exhibition, lyvaskyla, Finland.

Jasiulewicz, M. (2004). Feasibilities of Marginal Soils Usage by Energy Plants Cultivation in West Pomeranian Voivodeship. W: Trends in International Economy Relations in Agriculture and Food Economy. Warszawa.

Jasiulewicz, M. (2005). Renewed Energy from Energy Plants. 14th European Biomass Conference and Exhibition Biomass for Energy Industry and Climate Protection, Paris.

Jasiulewicz, M. (2008). Economical Aspects of the Short Rotation Coppices of Willow and Results of Co-combustion Process in the Middle Boiler. W: European Biomass Conference \& Exhibition (p. 310-313). Valencia, Spain.

Jasiulewicz, M. (2010a). Possibility of Liquid Bio-Fuels, Electric and Heat Energy Production from Biomass in Polish Agricultura, Polish Journal of Environmental Studies, 19(3), 479-483.

Jasiulewicz, M. (2010b). Potential of Biomass in Poland. Koszalin: Koszalin University of Technology. 